Article

\title{
Synthesis and Effects of Two Novel Rare-Earth Energetic Complexes on Thermal Decomposition of Cyclotetramethylene Tetranitramine (HMX)
}

\author{
Xuefang Cao ${ }^{1}$, Zhixian Wei ${ }^{1, *}$, Jiangfeng Song ${ }^{2, *}$, Hedan Zhang ${ }^{1}$, Yuanyuan $\mathrm{Qu}^{2}$ and Fei Xie ${ }^{2}$ \\ 1 School of Environment and Safety Engineering, North University of China, Taiyuan 030051, China; \\ s1714035@st.nuc.edu.cn (X.C.); s1604037@st.nuc.edu.cn (H.Z.) \\ 2 School of Science, North University of China, Taiyuan 030051, China; s1408060@st.nuc.edu.cn (Y.Q.); \\ s1508053@st.nuc.edu.cn (F.X.) \\ * Correspondence: zx_wei@126.com (Z.W.); jfsong0129@nuc.edu.cn (J.S.)
}

Received: 30 April 2020; Accepted: 17 June 2020; Published: 22 June 2020

\begin{abstract}
In order to explore the effect of the energetic complex on the thermal decomposition HMX, two new rare-earth energetic complexes $\left[\mathrm{La}(\mathrm{tza})\left(\mathrm{NO}_{3}\right)_{2}\left(\mathrm{H}_{2} \mathrm{O}\right)_{4}\right]_{n}(\mathbf{1})$ and $\left[\mathrm{Ce}(\mathrm{tza})\left(\mathrm{NO}_{3}\right)_{2}\left(\mathrm{H}_{2} \mathrm{O}\right)_{4}\right]_{n}(\mathbf{2})$ $(\mathrm{Htza}=$ tetrazole-1-acetic acid $)$ were prepared by a solvent evaporation method. The obtained products were structurally characterized by Fourier-transform infrared spectroscopy (FTIR), elemental analysis, powder X-ray diffraction (PXRD), single crystal X-ray diffraction (XRD), and thermogravimetric analysis coupled with differential scanning calorimetry (TG-DSC). In addition, the compatibility of complex 1 with cyclotetramethylene tetranitramine (HMX) was studied by DSC and FTIR, respectively. Structural analysis suggested that complex 1 exhibits an orthorhombic, $\mathrm{P} 22_{1} 2_{1} 2_{1}$ space group, and the $\mathrm{La}$ (III) ion was 10-fold coordinated in a distorted double-capped antiprism configuration. Complex 2 featured a one-dimensional, right-handed helical infinite chain. The effect of complexes $\mathbf{1}$ and $\mathbf{2}$ on the thermal decomposition of HMX was investigated by DSC, which revealed that complex 1 showed a slightly better effect than 2 on the thermal decomposition of HMX and released more heat. Furthermore, complex $\mathbf{1}$ had good compatibility with HMX, indicating that it may act as a combustion promoter for nitrate ester plasticized polyether (NEPE) solid propellant.
\end{abstract}

Keywords: energetic complex; HMX; promoter; compatibility

\section{Introduction}

Nitrate ester plasticized polyether (NEPE) propellant is a new type of crosslinked, high-energy, solid propellant which uses polyether polyurethane as a binder, nitrate esters as plasticizers, and is filled with a large amount of the high-energy oxidant, cyclotetramethylene tetranitramine (HMX) [1-3]. It also contains a combustion agent, stabilizer, and combustion promoter [4]. Here, HMX is used as the main component of the NEPE solid propellant, and a large amount of HMX increases the pressure index of the propellant, so improving the thermal degradation properties of HMX will significantly improve the combustion performance of NEPE [5-7]. Although the combustion promoter accounts for only a small proportion of solid propellants (about $2 \%-5 \%$ ), it can greatly improve their combustion performance [8-10], so studying the type and performance of combustion promoters is highly important.

Energetic metal complexes are generally assembled with energetic ligands and metal ions, which are synthesized by different coordination techniques to give them certain spatial structures. They also have stable structures and superior thermal stabilities, suggesting they may be used in explosives [11]. On one hand, the energy released by the complexes can provide additional energy during the thermal decomposition of HMX or the combustion of NEPE. The energy can also be used 
to decompose more active metal oxides in situ to promote the combustion of NEPE, which would result in a lower pressure exponent and improvement in the combustion performance of the solid propellants $[12,13]$. Therefore, when used as combustion promoters that provided a platform for making various nanostructures, energetic metal complexes have very promising prospects [14-16]. This has led to the preparation of many energetic metal complexes, and their promoter properties for the thermal decomposition of HMX; hexahydro-1, 3, 5-trinitro-1, 3, 5-triazine (RDX); and ammonium perchlorate (AP) have been studied. Two kinds of Ni(II) salt complexes were synthesized using tetrazole derivative 5,5'-azotetrazole (AZT) as a ligand, which respectively lowered the temperature of the exothermic peaks of HMX and increased the heat of decomposition [17]. Two $\mathrm{Cu}$ (I)/Cu(II) coordination compounds [18] were shown to have an obvious effect on the thermolysis of HMX. It has shown that when HMX is mixed with LLM-105, fluoroelastomer, or powdered aluminum, respectively, the decomposition peak temperature decreased [19]. Two $\mathrm{Cu}(\mathrm{II})$ compounds [20] based on an azole ligand were shown to accelerate the thermal decomposition of RDX. A Ni(II) coordination compound based on pyridyl-triazole [21], and two $\mathrm{Pb}$ (II) compounds based on 3-(tetrazol-5-yl) triazol [22] were good candidates for use as promoters of AP thermolysis.

Among nitrogen-rich organic ligands of energetic complexes, tetrazolium heterocyclic complexes have many coordination points, which allow them to be coordinated as neutral molecules or as aprotic anions. This facilitates the formation of high-dimensional structures by connecting independent or low-dimensional coordination units. Moreover, tetrazole rings can act as hydrogen bond donors or acceptors, which help increase the density and stability of the complexes [23-26]. Four new rare earth polymers- $\left[\mathrm{La}(\mathrm{tza})_{3}\left(\mathrm{H}_{2} \mathrm{O}\right)_{2} \cdot 2 \mathrm{H}_{2} \mathrm{O}\right]_{n},\left[\mathrm{Pr}(\mathrm{tza})_{3}\left(\mathrm{H}_{2} \mathrm{O}\right)_{2} \cdot 2 \mathrm{H}_{2} \mathrm{O}\right]_{n},\left[\mathrm{Nd}(\mathrm{tza})_{3}\left(\mathrm{H}_{2} \mathrm{O}\right)_{2} \cdot 1 \cdot 5 \mathrm{H}_{2} \mathrm{O}\right]_{n}$, and $\left[\mathrm{Sm}_{2}(\mathrm{tza})_{6}\left(\mathrm{H}_{2} \mathrm{O}\right)_{5} \cdot \mathrm{H}_{2} \mathrm{O}\right]_{n}$-were synthesized by reaction of Htza with oxides of rare earth [27]. A series of lanthanide-based complexes- $\left[\mathrm{Ln}(\text { atza })_{2}\left(\mathrm{CH}_{3} \mathrm{OH}\right)\left(\mathrm{H}_{2} \mathrm{O}\right) \mathrm{Cl}\right][\mathrm{Ln}=\mathrm{Pr}, \mathrm{Nd}, \mathrm{Sm}],\left[\mathrm{Ln}(\text { atza })_{2}\left(\mathrm{H}_{2} \mathrm{O}\right)_{3}\right] \mathrm{Cl}$ $[\mathrm{Ln}=\mathrm{Eu}, \mathrm{Gd}]$, and $\left[\mathrm{Tb}(\mathrm{atza})_{2}\left(\mathrm{H}_{2} \mathrm{O}\right)_{4}\right] \mathrm{Cl}$-were synthesized by reaction of $\mathrm{LnCl}_{3} \cdot 6 \mathrm{H}_{2} \mathrm{O}$ with 5-aminotetrazole-1-acetic acid (Hatza) under the alkaline condition [28]. Therefore, carboxylate tetrazole compounds are excellent ligands for the construction of novel versatile complexes. As an energetic ligand, Htza can coordinate with different metal atoms. Its $\mathrm{N}$ atom can strongly coordinate with transition metals, while its $\mathrm{O}$ atom coordinates with rare earth metal ions. Recently, our team has also reported a series of energetic tetrazole complexes, including $\left[\mathrm{Co}(\mathrm{tza})_{2}\right]_{n},\left[\mathrm{Bi}(\mathrm{tza})_{3}\right]_{n}$ and $\left[\mathrm{Fe}_{3} \mathrm{O}(\mathrm{tza})_{6}\left(\mathrm{H}_{2} \mathrm{O}\right)_{3}\right] \mathrm{NO}_{3}$ [29]. However, fewer compounds acted as additives to $\mathrm{HMX}$ are reported for rare earth metals.

The addition of $\mathrm{La}_{2} \mathrm{O}_{3}$ to the catalyst carrier $\mathrm{Al}_{2} \mathrm{O}_{3}$ has been shown to have a good effect on automobile exhaust [30]. Cerium oxides have been successfully used to catalyze the redox reaction of $\mathrm{CO}$ and $\mathrm{N}_{x} \mathrm{O}$ [31]. The main pollutants emitted by vehicles are $\mathrm{CO}$ and $\mathrm{NO}_{x}$ complexes, which are very similar to the thermal decomposition products of HMX [32]. Thus, it is expected that $\mathrm{La}(\mathrm{III})$ and $\mathrm{Ce}(\mathrm{III})$ complexes may be good combustion promoters for NEPE. Therefore, in this study, Htza was used as a ligand, and La and Ce as central ions to construct two rare-earth energetic complexes.

The compatibility between the energetic additives and other propellant components is the key to making stable and practical propellants. Good compatibility is achieved when additives have good long-term stability and uniformity in a system. In contrast, unexpected explosions due to decomposition reactions may occur [33]. Therefore, the compatibility of new complexes and HMX should be investigated further. One of the most commonly used methods for analyzing the compatibility of energetic materials is differential scanning calorimetry (DSC). Since DSC is convenient, efficient, safe, and requires only small sample quantities, it has broad applications and is also a common method for judging the phase properties of energetic materials. In addition, some non-thermal techniques, such as Fourier-transform infrared spectroscopy (FTIR), have been frequently used to expand the understanding of thermal behavior that is not observed at room temperature [34,35]. One of the purposes of this study was to investigate previously unreported compatibility data for interactions between complexes and HMX using DSC combined with FTIR. Such information can assist in the design and optimization of future propellant additives. 


\section{Materials and Methods}

The experimental materials were all analytical grade and commercially available. The purity of all reagents was verified by a Vario ELIII elemental analyzer (Elementar, Hanau, Germany). Samples for FTIR were analyzed on an imported spectrometer. Powder X-ray diffraction (PXRD) patterns were obtained using $\mathrm{Cu} \mathrm{K} \alpha$-ray using monochromatic graphite at room temperature. In this study, the thermal decomposition performance of complexes was evaluated in the range from $40-400{ }^{\circ} \mathrm{C}$ under flowing $\mathrm{N}_{2}$ at $20 \mathrm{~mL} \cdot \mathrm{min}^{-1}$.

\subsection{Synthesis of $\left[\mathrm{La}(t z a)\left(\mathrm{NO}_{3}\right)_{2}\left(\mathrm{H}_{2} \mathrm{O}\right)_{4}\right]_{n}(\mathbf{1})$ and $\left[\mathrm{Ce}(t z a)\left(\mathrm{NO}_{3}\right)_{2}\left(\mathrm{H}_{2} \mathrm{O}\right)_{4}\right]_{n}$ (2)}

A solution using acetonitrile solvent $(5 \mathrm{~mL})$ containing Htza $(0.01281 \mathrm{~g}, 0.1 \mathrm{mmol})$ and $\mathrm{La}\left(\mathrm{NO}_{3}\right)_{3} \cdot 6 \mathrm{H}_{2} \mathrm{O}(0.02165 \mathrm{~g}, 0.05 \mathrm{mmol})$, was filtered after the addition of four drops of distilled water. The filtrate was sealed with plastic wrap, punctured, and then slowly evaporated at room temperature. After two days, colorless prism crystals were collected. Yield: 50\% (based on La). $\mathrm{C}_{3} \mathrm{H}_{11} \mathrm{LaN}_{6} \mathrm{O}_{12}$ (462.09); $\mathrm{C} 7.76$ (calc. 7.79); $\mathrm{H} 2.51$ (2.38); $\mathrm{N} 18.33$ (18.18)\%.

An acetonitrile liquor $(10 \mathrm{~mL})$ containing $\mathrm{Ce}\left(\mathrm{NO}_{3}\right)_{3} \cdot 6 \mathrm{H}_{2} \mathrm{O}(0.0434 \mathrm{~g}, 0.1 \mathrm{mmol})$ was added dropwise to a mixture of acetonitrile $(10 \mathrm{~mL})$ containing Htza $(0.0768 \mathrm{~g}, 0.6 \mathrm{mmol})$. The mixed solution was stirred for $1 \mathrm{~h}$ and then filtered. The filtrate was sealed with plastic wrap, punctured, and then slowly evaporated at room temperature, which was allowed to evaporate slowly at room temperature, and after two days, colorless prism crystals were collected. Yield: $80 \%$ (based on Ce). $\mathrm{CeC}_{3} \mathrm{H}_{11} \mathrm{~N}_{6} \mathrm{O}_{12}$ (463.30); C, 7.96 (calc. 7.77); H, 2.12 (2.37); N, 18.38 (18.13)\%.

\subsection{X-ray Single-Crystal Diffraction (XRD)}

Complexes were analyzed by a SMART-1000 X-ray diffractometer (BRUKER ASX, Karlsruhe, Germany). At 298 (2) K, the sample was scanned by Mo $K \alpha$ ray $(\lambda=0.71073 \AA)$ in the form of $\omega / 2 \theta$. All single-crystal structures were solved by direct methods and anisotropically refined using a full-matrix least-squares $\mathrm{F}^{2}$ method using SHELXTL-97. All non-H atoms were refined in a full-matrix anisotropic thermal parameters approximation. The $\mathrm{H}$ atoms of the ligands were obtained using a riding model, while disordered $\mathrm{tza}^{-}$and $\mathrm{NO}_{3}{ }^{-}$in complexes were refined by performing split and occupancies refinement.

\subsection{Fourier-Transform Infrared Spectroscopy (FTIR)}

Samples were analyzed by an FTIR-84005 spectrometer (Shimadzu, Tokyo, Japan) from the spectral region $4000-400 \mathrm{~cm}^{-1}$, with a resolution of $0.4 \mathrm{~cm}^{-1}$, using $\mathrm{KBr}$ pellets.

\subsection{X-ray Powder Diffraction (PXRD)}

Complexes were measured by graphite monochromatic $\mathrm{Cu} \mathrm{K} \alpha$ ray with a tube pressure of $40 \mathrm{kV}$ and a tube flow of $100 \mathrm{~mA}$ on a Rigaku D/max-rA X-ray diffractometer (Rigaku, Tokyo, Japan).

\subsection{TG-DSC Thermal Analysis}

Samples were analyzed on a Mettler Toledo GC10 TG-DSC (Mettler Toledo, DE, USA). Complex $(0.7 \mathrm{mg})$ was added to a closed platinum crucible and measured under a flowing $\mathrm{N}_{2}$ atmosphere $\left(20 \mathrm{~mL} \cdot \mathrm{min}^{-1}\right)$ at a heating rate of $10 \mathrm{~K} \cdot \mathrm{min}^{-1}$.

\subsection{Effect of the Energetic Complexes on Thermal Degradation of HMX}

To evaluate how the energetic complexes facilitated the thermal degradation of HMX, HMX was mixed with the synthetic complexes at a 19:1 mass ratio. The amount of the promoter used in this experiment on the Mettler Toledo DSC823E was similar to the amount of a typical catalyst, which was about $5 \%$ (mass ratio). 


\subsection{Compatibility Test between HMX and Complex $\mathbf{1}$}

Since complex $\mathbf{1}$ had a more pronounced effect on the thermal decomposition of HMX than $\mathbf{2}$, the compatibility of complex $\mathbf{1}$ and HMX was then studied by DSC and FTIR [36]. A sample was obtained by mechanically mixing and grinding complex 1 with $\mathrm{HMX}$ at 1:1 mass ratio for 5 min to maximize all possible interactions between complex 1 and HMX.

\section{Results and Discussion}

\subsection{Structure Descriptions}

\subsubsection{Structures of $\left[\mathrm{La}(\mathrm{tza})\left(\mathrm{NO}_{3}\right)_{2}\left(\mathrm{H}_{2} \mathrm{O}\right)_{4}\right]_{n}(\mathbf{1})$}

Complex 1 crystallizes in an orthorhombic space group P $2_{1} 2_{1} 2_{1}$. The asymmetric unit of the complex includes two independent $\mathrm{La}(\mathrm{III})$ ions, one tza ${ }^{-}$ligand, two $\mathrm{NO}_{3}{ }^{-}$ions, and four water molecules (Figure 1). The La(III) ion is 10-fold coordinated and located in a distorted double-capped antiprism configuration (Figure 1a), with the capping position occupied by two $\mathrm{O}$ atoms (O2 and $\mathrm{O} 5$ ) from two different $\mathrm{NO}_{3}{ }^{-}$groups. One surface of the antiprism is composed of four $\mathrm{O}$ atoms $(\mathrm{O} 7, \mathrm{O} 8$, $\mathrm{O} 9 \mathrm{~W}$, and O1) from two different tza- groups, one coordinated water, and one $\mathrm{NO}_{3}{ }^{-}$group. The other is composed of four $\mathrm{O}$ atoms $(\mathrm{O} 10 \mathrm{~W}, \mathrm{O} 11 \mathrm{~W}, \mathrm{O} 12 \mathrm{~W}$, and $\mathrm{O} 4)$ from three coordinated waters and one $\mathrm{NO}_{3}{ }^{-}$group. The crystallographic data and detailed information of complexes are contained in Table S1, and selected bond information is shown in Supplementary Materials Table S2.

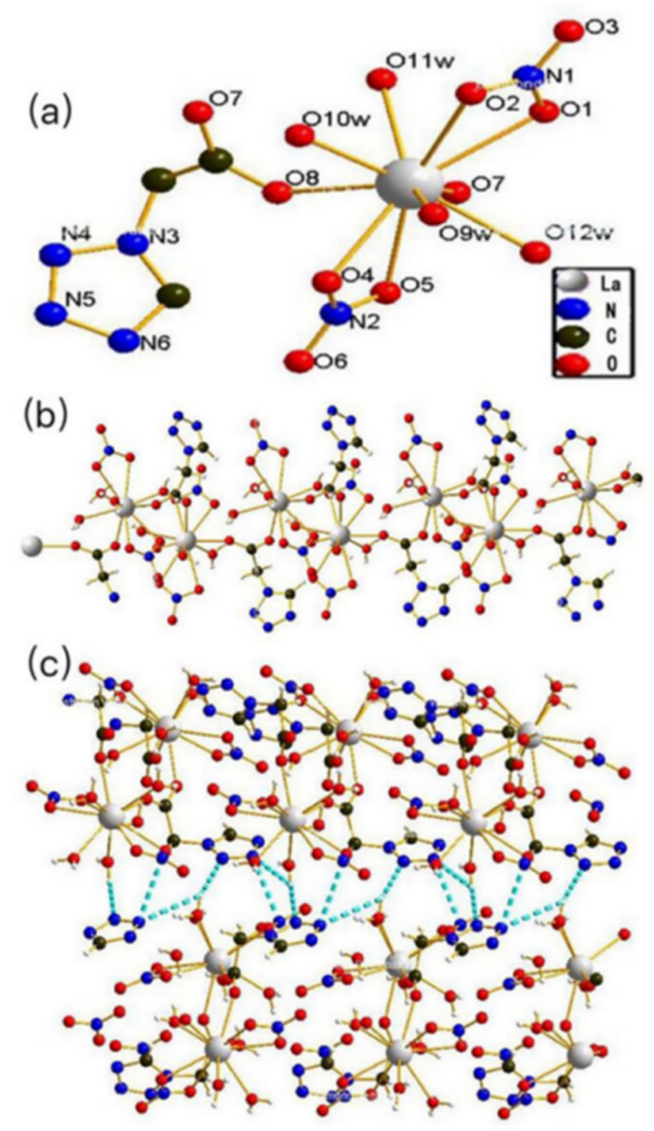

Figure 1. (a) The coordination environment of La(III); (b) one-dimensional chain of complex 1 with left-handed chirality; (c) three-dimensional network structure of complex $\mathbf{1}$ connected by O-H ... N hydrogen bonds. 


\subsubsection{Structures of $\left[\mathrm{Ce}(\mathrm{tza})\left(\mathrm{NO}_{3}\right)_{2}\left(\mathrm{H}_{2} \mathrm{O}\right)_{4}\right]_{\mathrm{n}}(2)$}

The asymmetric structure of complex 2 includes one $\mathrm{Ce}(\mathrm{III})$ ion, one tza ${ }^{-}$, two $\mathrm{NO}_{3}{ }^{-}$, and four coordinated water molecules. The Ce(III) ion is 10-fold coordinated and located in a distorted double-capped antiprism configuration (Figure 2a). The capping position is occupied by two $\mathrm{O}$ atoms (O3 and O6) from two different $\mathrm{NO}_{3}{ }^{-}$groups. One square plane of the antiprism is formed by four $\mathrm{O}$ atoms $(\mathrm{O} 1, \mathrm{O} 2, \mathrm{O} 1 \mathrm{~W}$, and $\mathrm{O} 4)$ from two different tza ${ }^{-}$groups, one coordinated water, and one $\mathrm{NO}_{3}{ }^{-}$ group. The other positions are occupied by four $\mathrm{O}$ atoms $(\mathrm{O} 2 \mathrm{~W}, \mathrm{O} 3 \mathrm{~W}, \mathrm{O} 4 \mathrm{~W}$, and $\mathrm{O} 7)$. The selected bond information is shown in Table S2.

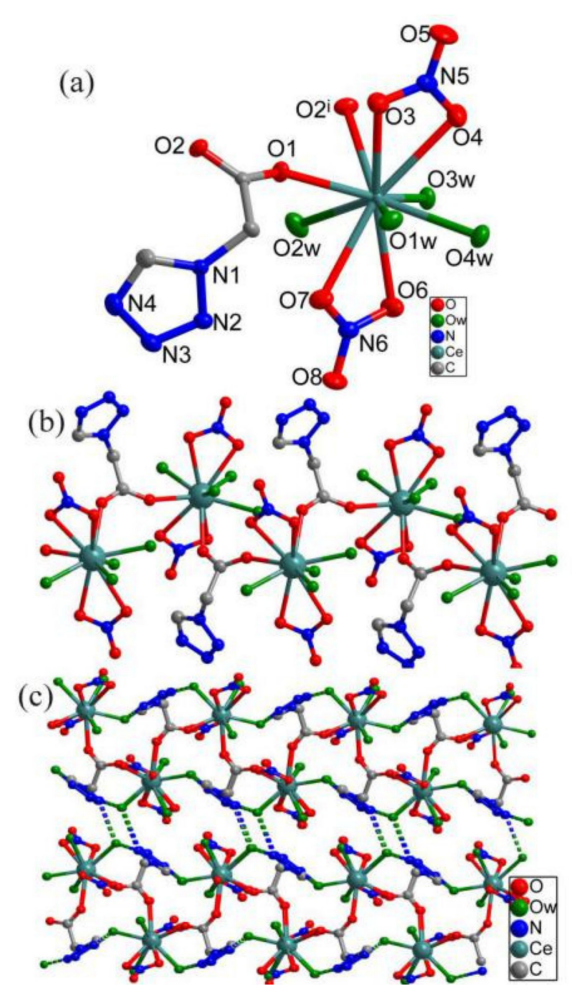

Figure 2. (a) The coordination environment of Ce with 50\% ellipsoids; (b) one-dimensional chain with left-handed chirality; (c) three-dimensional network of 2 formed by $\mathrm{O}-\mathrm{H} \ldots$. N hydrogen bonds.

As shown in Figure $2 b$, the tza- anions connect with $\mathrm{Ce}^{3+}$ cations to form a 1-D infinite chain, which has a left-handed helical configuration along the $b$ direction with adjacent $C e$ atoms separated by 6.10 Å. Each 1-D helical chain interacts with neighboring ones via O-H . . N Nydrogen bonds between water molecules and $\mathrm{tza}^{-}$anions which leads to the formation of an extended 3-D supramolecular structure (Figure 2c). The corresponding bond information is listed in Table S2. Supplementary Materials of this article include X-ray crystallographic files in CIF reports, crystal data, and structure refinement for the complex, selected bond lengths, and bond angles in Supplementary Materials. CCDC no.18881025 for $\mathbf{1}$ and 1524937 for 2.

\subsection{Fourier-Transform Infrared Spectroscopy (FTIR)}

The FTIR spectrum of complex 1 has a wide characteristic absorption band from $3000 \mathrm{~cm}^{-1}$ to $3600 \mathrm{~cm}^{-1}$ (Figure 3), which corresponds to the $\mathrm{O}-\mathrm{H}$ stretching vibration and the formation of hydrogen bonds between crystalline water and coordinated water in $\left[\mathrm{La}(\mathrm{tza})\left(\mathrm{NO}_{3}\right)_{2}\left(\mathrm{H}_{2} \mathrm{O}\right)_{4}\right]_{n}$. The $\mathrm{HOH}$ bending vibration peak is at $1627 \mathrm{~cm}^{-1}$ [37]. The asymmetric stretching absorption vibration of Htza at $1720 \mathrm{~cm}^{-1}$ shifted to around $1600 \mathrm{~cm}^{-1}$, mainly due to the coordination of a La ion with an $\mathrm{O}$ atom in $\mathrm{C}(\mathrm{O}) \mathrm{O}^{-}$. Due to the symmetrical stretching vibration of $\mathrm{C}=\mathrm{O}$, an absorption peak can be seen near $1454 \mathrm{~cm}^{-1}$. The absorption peaks near $815 \mathrm{~cm}^{-1}$ appeared due to the in-plane bending 
vibration of $-\mathrm{COOH}(\delta(\mathrm{C}=\mathrm{O}))$. The absorption peak near $1332 \mathrm{~cm}^{-1}$ is the symmetrical vibration peak of $-\mathrm{NO}_{3}[38]$. The above analysis is consistent with the synthesized crystal structure.

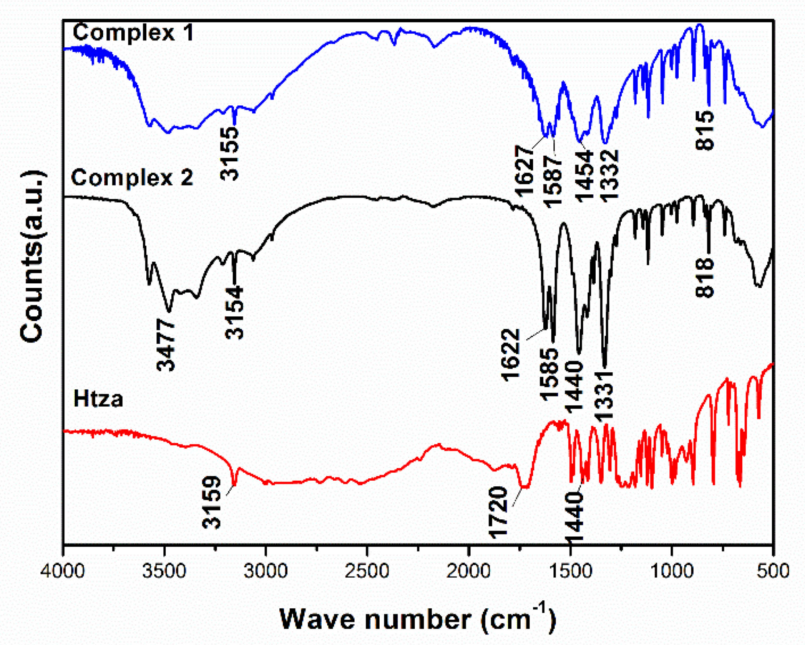

Figure 3. FTIR spectra of Htza, complex 1, and complex 2.

Since an $\mathrm{O}$ atom in $\mathrm{C}(\mathrm{O}) \mathrm{O}^{-}$coordinated with a $\mathrm{Ce}$ ion, the stretching vibration of $\mathrm{C}=\mathrm{O}$ in $\mathrm{Htza}$ shifted from $1720 \mathrm{~cm}^{-1}$ to around $1600 \mathrm{~cm}^{-1}$. The absorption peak near $1440 \mathrm{~cm}^{-1}$ appeared due to the symmetrical stretching vibration of $\mathrm{C}=\mathrm{O}$. The stretching vibration peak of $-\mathrm{COOH}$ was redshifted, which indicates that the $\mathrm{C}(\mathrm{O}) \mathrm{O}^{-}$coordinated with Ce ions to form complex 2 [27]. The peak at $1622 \mathrm{~cm}^{-1}$ is due to the bending vibration of $\mathrm{HOH}$ [37]. The symmetrical absorption vibration peak of $-\mathrm{NO}_{3}$ is between 1300 and $1500 \mathrm{~cm}^{-1}$ [38] (Figure 3).

\subsection{PXRD Diffraction Analysis}

The purity of complexes 1 and 2 were analyzed by comparing the simulated diffraction data (the red one) with the experimental powder diffraction data (the black one). The simulated data and the experimental data of complexes $\mathbf{1}$ and $\mathbf{2}$ were consistent, respectively, indicating that the two complexes were both pure (Figure 4).
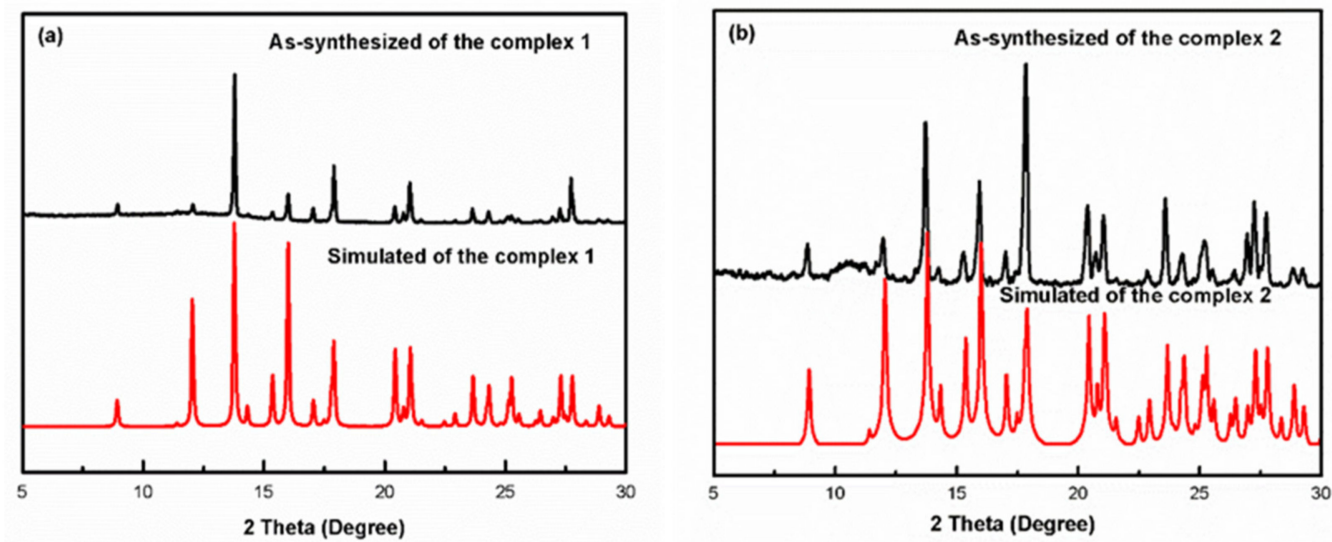

Figure 4. As-synthesized and simulated X-ray diffraction patterns of complexes $\mathbf{1}$ and 2.

\subsection{TG-DSC Thermal Analysis of Energetic Complexes $\mathbf{1}$ and $\mathbf{2}$}

TG-DSC was used to investigate the thermal stability and degradation mechanism of complexes 1 and 2 (Figure 5). The TG curve of complex 1 is divided into three parts. During the first part, the weight loss ratio of coordinated water was $15.2 \%$ from 100 to $207^{\circ} \mathrm{C}$, which was similar to the theoretical value 
of $15.5 \%$. In the second part, the tza- ligands of complex 1 began to decompose, causing the complex framework to collapse between $207^{\circ} \mathrm{C}$ to $450^{\circ} \mathrm{C}$. Significant mass loss occurred during this process, and it is inferred that the complex underwent a violent decomposition reaction within this temperature range. The frame of complex 1 collapsed, decomposed into solid products, and released gaseous products and heat. In the third stage, the TG curve was relatively stable from 450 to $600{ }^{\circ} \mathrm{C}$. The whole process contained two distinct peaks in the DSC curve: one endothermic peak at $137.3^{\circ} \mathrm{C}$ and one exothermic peak at $277.7^{\circ} \mathrm{C}$. Mass loss occurred due to the further decomposition of products from the second stage as the temperature continued to increase. The remaining $35.8 \%$ weight corresponded to the weight content of $\mathrm{La}_{2} \mathrm{O}_{3}$ (calcd. 35.3\%). The decomposition peak temperature of complex 1 was $277.7^{\circ} \mathrm{C}$ with a heat release of $1549 \mathrm{~J} \cdot \mathrm{g}^{-1}$.
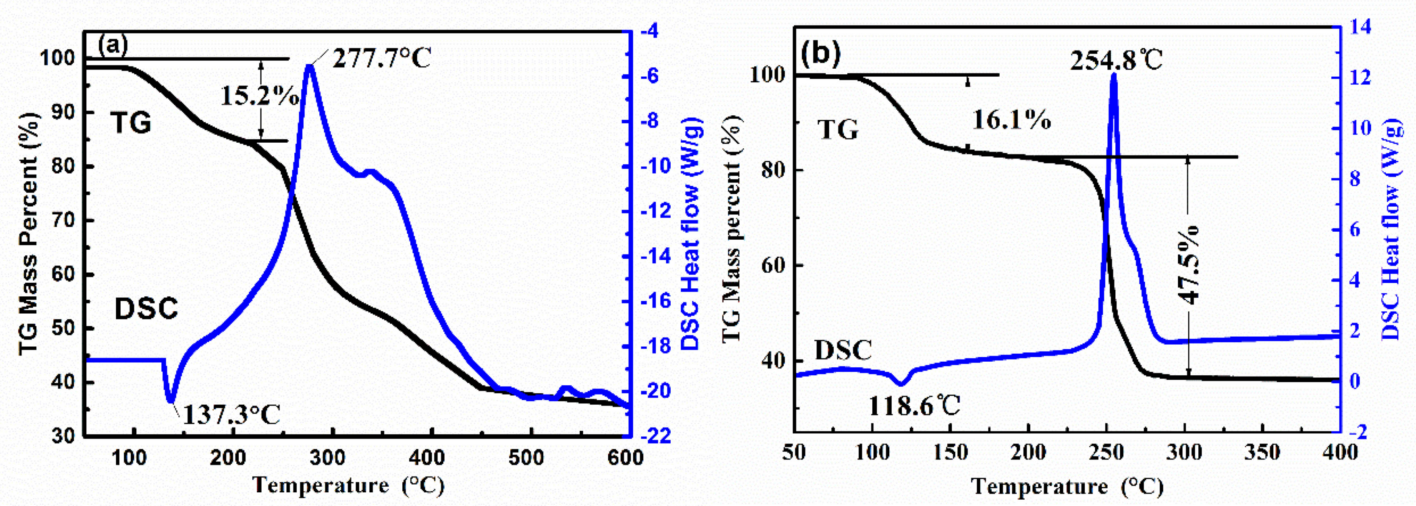

Figure 5. TG-DSC curves of complexes 1 (a) and 2 (b).

The TG data of complex 2 shows that initial weight loss occurred from $79.1-164.1^{\circ} \mathrm{C}$. The weight loss during this temperature increase was about $16.1 \%$, corresponding to a loss of four coordinated $\mathrm{H}_{2} \mathrm{O}$ molecules (calcd. 15.6\%). Complex 2 continued to decompose with continuous heating because of the decomposition of $\mathrm{NO}_{3}{ }^{-}$. The weight loss process corresponded to the exothermic peak at $254.8^{\circ} \mathrm{C}$ on the DSC curve. The remaining $36.4 \%$ of weight corresponds to the residual weight of $\mathrm{Ce}_{2} \mathrm{O}_{3}$, which is similar to the calculated value $35.4 \%$. From Figure 5, it can be seen that the exothermic peak temperature of complex 2 is $254.8^{\circ} \mathrm{C}$, with a decomposition heat of $930.1 \mathrm{~J} \cdot \mathrm{g}^{-1}$. The experimental data reveals that both complex $\mathbf{1}$ and $\mathbf{2}$ have high decomposition temperatures and release high amounts of energy, indicating that they are thermally stable energetic complexes.

\subsection{Effect of Energetic Complexes $\mathbf{1}$ and $\mathbf{2}$ on Thermal Degradation of HMX}

Complexes 1 and $\mathbf{2}$ were mixed with HMX at a 1:19 mass ratio to investigate how they affected the thermal degradation of HMX using DSC. From the DSC curve of pure HMX, it can be seen that the decomposition process contains two endothermic peaks and one exothermic peak (Figure 6). One of the endothermic peaks at $194.3^{\circ} \mathrm{C}$ was attributed to the crystal transformation of HMX, while the other endothermic peak at $278.2^{\circ} \mathrm{C}$ was due to the liquid phase degradation of HMX [39]. The exothermic peak occurred at $282.6^{\circ} \mathrm{C}$, with a heat release of $1198.3 \mathrm{~J} \cdot \mathrm{g}^{-1}$, which is nearly identical to the decomposition process of HMX reported in previous studies $[18,40]$. Energy can be obtained by integrating the area of Figure 6. By using the following formula, the actual increase or decrease of the heat release of the system can be obtained:

$$
\Delta H\left(\mathrm{~J} \cdot \mathrm{g}^{-1}\right)=H_{\mathrm{t}}-\left(5 \% \times H_{\mathrm{n}}+95 \% \times \mathrm{H}_{0}\right)
$$

where $\Delta H$ is the actual added heat release of the system, $H_{\mathrm{t}}$ is the total heat release of the mixed system, $H_{\mathrm{n}}$ is the heat release of the complex 1 or 2 and $H_{0}$ is the heat release per gram of HMX. 


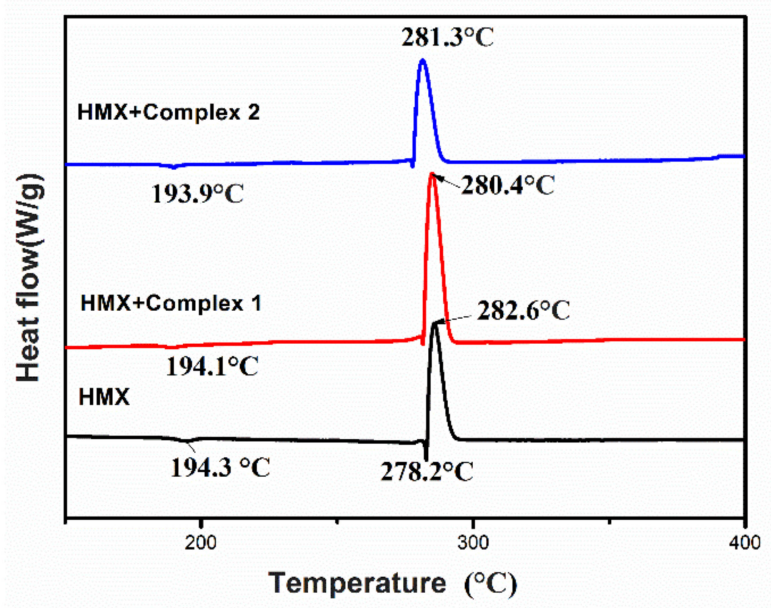

Figure 6. DSC curves of the HMX, HMX with complex $\mathbf{1}$ and HMX with complex 2.

However, the effects of compound $\mathbf{1}$ and $\mathbf{2}$ for HMX thermal decomposition could be explained as follows: (1) In the thermal decomposition processes of HMX with 1 and 2, respectively, fresh metal oxides at the molecule level can be formed (Figure 5). The in-situ formed oxides with a high specific surface have high density of active sites on the surface and can play an important catalytic role. On the other hand, those fresh metal oxide powders would trap HMX as more adsorption sites formed. Such effects would make HMX less stable and result in the decrease of the decomposition peak temperatures of HMX and HMX mixtures. Furthermore, the formed fresh metal oxides can also adsorb more pyrolysis products of $\mathrm{HMX}$ and lead to the release of the adsorption heat [41]. (2) The main gaseous products of $\mathrm{HMX}$ are $\mathrm{CH}_{2} \mathrm{O}, \mathrm{NO}_{2}, \mathrm{CO}_{2}, \mathrm{NO}, \mathrm{CO}$, and $\mathrm{N}_{2} \mathrm{O}$ [42-44]. It is noted that the thermal decomposition products of HMX are similar to those of automobile exhaust. Owing to $\mathrm{La}_{2} \mathrm{O}_{3}$ and $\mathrm{Ce}_{2} \mathrm{O}_{3}$ being able to catalyze the reactions of carbon oxides and nitrogen oxides in automobile exhaust $[30,31]$. One can conclude that a serious of exothermic reactions between the different gaseous products could be catalyzed with those fresh metal oxide mixtures, including the oxidation reaction of $\mathrm{CO}$, the reaction between $\mathrm{CO}$ and NO, and so on. That could lead to the increase of heat release.

Compared with the DSC curve in Figure 6, the position of the first endothermic peak of HMX was nearly unchanged after complex $\mathbf{1}$ was added, which indicates that the addition of complex 1 had no effect on the crystal transition process of HMX. As an additive, complex 1 not only reduced the exothermic peak temperature of $\mathrm{HMX}$ by $2.2{ }^{\circ} \mathrm{C}$, but also increased the heat release of HMX by $129.9 \mathrm{~J} \cdot \mathrm{g}^{-1}$ (Table 1). Therefore, the complex could promote the thermal degradation of HMX. When complex 2 was added, the exothermic peak temperature of HMX increased $1.3{ }^{\circ} \mathrm{C}$, and the amount of liberated heat increased by $41.5 \mathrm{~J} \cdot \mathrm{g}^{-1}$. In addition, as an HMX addictive, the decomposition peak temperature reduction and heat release of the La complex (complex 1) is more and higher than that of some transition metal complexes, such as $[\mathrm{Ag}(\operatorname{tza})]_{n}(3),\left[\mathrm{Cu}(\operatorname{tza})_{2}\right]_{n}(4)$ and $\left[\mathrm{Zn}(\operatorname{tza})_{2}\right]_{n}(5)$ [45], under the same conditions.

Table 1. Promoting effect of complexes 1 to 5 on the thermal decomposition of HMX $[29,45]$.

\begin{tabular}{ccccc}
\hline Sample & $\boldsymbol{T}_{\text {exo }}\left({ }^{\circ} \mathbf{C}\right)$ & $\boldsymbol{H}^{\mathbf{1}}\left(\mathbf{J} \cdot \mathbf{g}^{-\mathbf{1}}\right)$ & $\Delta \boldsymbol{H}^{\mathbf{2}}\left(\mathbf{J} \cdot \mathbf{g}^{-\mathbf{1}}\right)$ & $\Delta \boldsymbol{T}^{\mathbf{3}}\left({ }^{\circ} \mathbf{C}\right)$ \\
\hline HMX & 282.6 & 1198.3 & - & - \\
HMX + complex 1 & 280.4 & 1345.7 & 129.9 & 2.2 \\
HMX + complex 2 & 281.3 & 1226.4 & 41.5 & 1.3 \\
HMX + complex 3 & 280.9 & 1286.3 & 109.8 & 1.7 \\
HMX + complex 4 & 281.0 & 1213.2 & 37.7 & 1.6 \\
HMX + complex 5 & 281.2 & 1234.3 & 53.1 & 1.4 \\
\hline
\end{tabular}

${ }^{1} \mathrm{H}$ : the heat release of HMX or a mixed system. ${ }^{2} \Delta \mathrm{H}$ : actual added heat value of the system with complexes 1 to 5 .

${ }^{3} \Delta \mathrm{T}$ : the change in the HMX decomposition peak temperature after the addition of complex 1 to 5. 
Since the two energetic complexes lowered the exothermic peak temperature of HMX and increased the amount of heat released, each can act as accelerators for the thermal decomposition of HMX. This suggests they may also be excellent combustion promoters of NEPE. Complex 1 exhibits a slightly better effect on the thermal degradation of HMX than $\mathbf{2}$ and lowers the decomposition temperature of HMX more and releases more heat under the same experimental conditions. Therefore, in this study, the compatibility between HMX and complex 1 was chosen for further study.

\subsection{Compatibility between HMX and Complex 1}

\subsubsection{DSC Analysis}

As shown in Figure 7, the difference between the exothermic peak temperature $\left(\Delta T_{\mathrm{p}}\right)$ of $\mathrm{HMX}$ and the mixture of complex 1 and $\mathrm{HMX}$ is $1.1^{\circ} \mathrm{C}$ (i.e., less than $2{ }^{\circ} \mathrm{C}$ ). According to the compatibility evaluation criteria of explosives and contact materials in Table 2, it is known that complex $\mathbf{1}$ has good compatibility with HMX and is safe for use in any explosive design when the exothermic peak temperature difference $\left(\Delta T_{\mathrm{p}}\right)$ is less than $2^{\circ} \mathrm{C}[46-48]$.

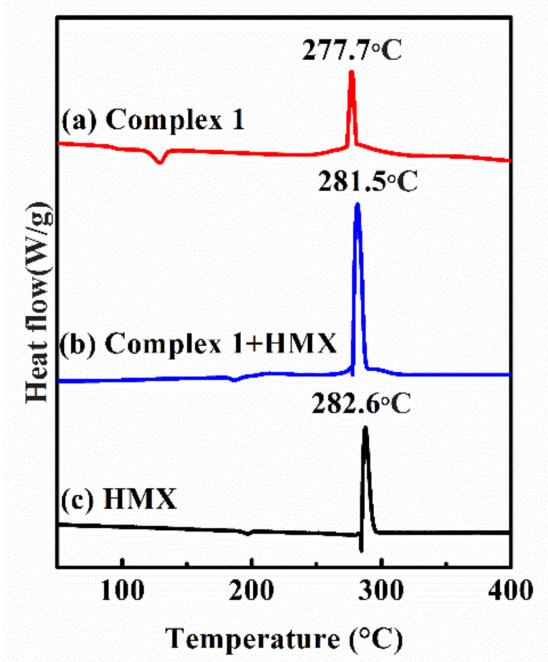

Figure 7. DSC curves for complex 1 (a), complex 1 and $\operatorname{HMX}(\mathbf{b})$, and pure $\operatorname{HMX}(\mathbf{c})$.

Table 2. Evaluated criterion of compatibility for explosives and energetic materials [36].

\begin{tabular}{cccc}
\hline Standard $\left(\Delta T_{\mathrm{p}} /{ }^{\circ} \mathrm{C}\right)$ & Rating & Safe for use in any explosive design. \\
\hline$\leq 2$ & A & $\begin{array}{c}\text { Compatible or good } \\
\text { compatibility }\end{array}$ & $\begin{array}{c}\text { Safe for use in testing, when the device is used in } \\
\text { a very short period of time; Not to be used as a } \\
\text { binder material, or when long-term storage is } \\
\text { desired. }\end{array}$ \\
\hline $3-5$ & B & $\begin{array}{c}\text { Slightly sensitized or fair } \\
\text { compatibility }\end{array}$ & Not recommended for use with explosive items. \\
\hline $6-15$ & C & $\begin{array}{c}\text { Sensitized or poor } \\
\text { compatibility }\end{array}$ & Hazardous. Do not use under any conditions. \\
\hline
\end{tabular}

\subsubsection{FTIR Method}

In this paper, the compatibility of $\left[\mathrm{La}(\mathrm{tza})\left(\mathrm{NO}_{3}\right)_{2}\left(\mathrm{H}_{2} \mathrm{O}\right)_{4}\right]_{n}$ with $\mathrm{HMX}$ was further studied using FTIR $[35,36]$. In Figure $8 \mathrm{a}$, due to the bending vibration and association of $\mathrm{O}-\mathrm{H}$ from crystalline and coordinated water, complex 1 exhibited a wider absorption peak near $3155 \mathrm{~cm}^{-1}$. The asymmetric vibrational $\mathrm{C}=\mathrm{O}$ peaks near 1627 and $1587 \mathrm{~cm}^{-1}$ show that the $\mathrm{O}$ atom in $\mathrm{C}(\mathrm{O}) \mathrm{O}^{-}$was successfully 
coordinated with the La ion. The absorption peak near $1454 \mathrm{~cm}^{-1}$ appeared due to the stretching vibration of $\mathrm{C}=\mathrm{N}$ in the tetrazole ring. In addition, the absorption peaks near $1332 \mathrm{~cm}^{-1}$ indicate that the La metal ion was successfully coordinated with $\mathrm{NO}_{3}{ }^{-}$[27]. In Figure 8c, the peaks near $3036 \mathrm{~cm}^{-1}$ were due to $\mathrm{C}-\mathrm{H}$ tensile vibration. The peaks near $1523 \mathrm{~cm}^{-1}$ and $759 \mathrm{~cm}^{-1}$ were due to $-\mathrm{NO}_{2}$ asymmetric, symmetric, and bending vibrations, respectively. The peaks near $1260 \mathrm{~cm}^{-1}$ were due to the stretching vibration of N-N [49]. In Figure 8b, no new absorption peak appeared, and the position of the peaks was nearly unchanged compared with those of HMX and complex 1. The absorption spectrum in Figure 8b was obtained by superimposing Figure 8a,c. Therefore, it was concluded that there was no chemical interaction between the pair of components [35]. Consequently, at room temperature, complex 1 does not interact with HMX, showing that the two compounds have good compatibility.

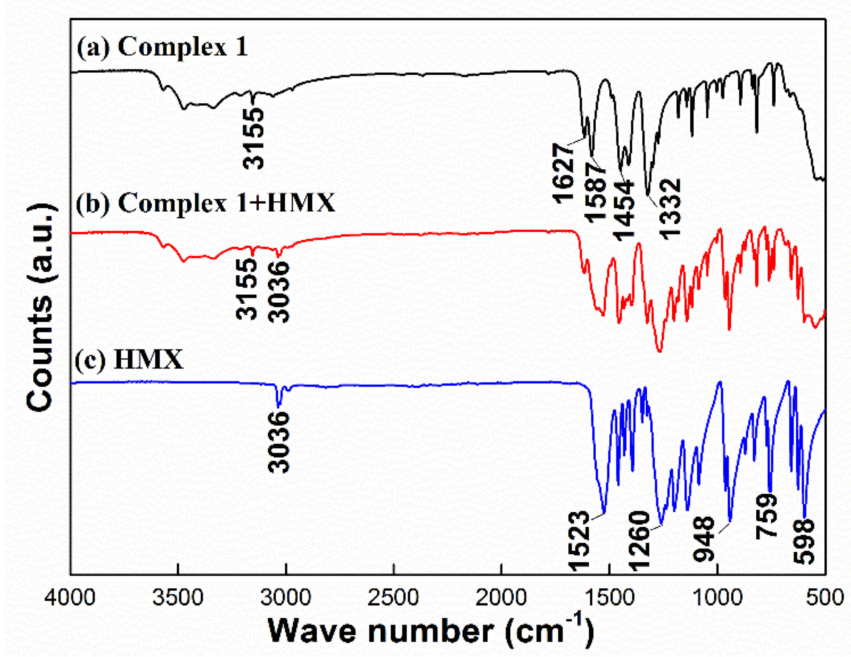

Figure 8. FTIR curves of complex 1 (a), complex 1 and $\operatorname{HMX}(\mathbf{b})$, and $\operatorname{HMX}(\mathbf{c})$.

\section{Conclusions}

Two novel, thermally-stable rare-earth energetic complexes $\left[\mathrm{La}(\mathrm{tza})\left(\mathrm{NO}_{3}\right)_{2}\left(\mathrm{H}_{2} \mathrm{O}\right)_{4}\right]_{n}$ and [Ce(tza) $\left.\left(\mathrm{NO}_{3}\right)_{2}\left(\mathrm{H}_{2} \mathrm{O}\right)_{4}\right]_{n}$ were prepared and evaluated. The two complexes were shown to promote the thermal degradation of HMX. Complex 1 showed a slightly better effect on the thermal decomposition of HMX than 2, and it was also compatible with HMX. These results show that $\left[\mathrm{La}(\mathrm{tza})\left(\mathrm{NO}_{3}\right)_{2}\left(\mathrm{H}_{2} \mathrm{O}\right)_{4}\right]_{\mathrm{n}}$ may be a more efficient combustion promoter for NEPE propellant. This study could provide beneficial ideas for the rational design and preparation of new energetic promoters for solid propellants.

Supplementary Materials: The following are available online at http://www.mdpi.com/1996-1944/13/12/2811/s1, Table S1: Crystal data and structure refinement for the complexes 1 and 2, Table S2: Selected Bond Distances $(\AA)$ and Angles $\left({ }^{\circ}\right)$ for complexes 1 and $\mathbf{2}$. The CIF reports of complexes 1 and $\mathbf{2}$ can be found in the supplementary materials.

Author Contributions: Conceptualization, Z.W.; Methodology, H.Z., Y.Q., F.X., and X.C.; Software, J.S.; Validation, H.Z., Y.Q., F.X., and X.C.; Formal Analysis, H.Z., Y.Q., F.X., and X.C.; Investigation, H.Z. and X.C.; Resources, H.Z., Y.Q., F.X., and X.C.; Data Curation, H.Z. and X.C; Writing-original draft preparation, H.Z. and X.C.; Writing-review and editing, X.C.; Visualization, X.C.; Supervision, Z.W.; Project Administration, Z.W.; Funding Acquisition, Z.W. All authors have read and agreed to the published version of the manuscript.

Funding: This work was funded by National Natural Science Foundation of China with grant No. $21371159,21201155$.

Conflicts of Interest: The authors declare no conflict of interest. 


\section{References}

1. Wu, W.E.; Chen, C.; Fu, X.; Ding, C.; Wang, G. The correlation between chemical stability and binder network structure in NEPE propellant. Propell. Explos. Pyrot. 2017, 42, 541-546. [CrossRef]

2. Li, H.; Li, Y.; Bai, L.F.; Huang, S.L.; Yan, G.Y.; Xie, L. Acceleration of $\delta$ - to $\beta$-HMX-D8 phase retransformation with D2O and intergranular strain evolution in a HMX-based polymer-bonded explosive. J. Phys. Chem. C 2019, 123, 6958-6964. [CrossRef]

3. Wu, X.W.; Liu, Z.C.; Zhu, W.H. Conformational changes and decomposition mechanisms of HMX-based cocrystal explosives at high temperatures. J. Phys. Chem. C 2020, 124, 25-36. [CrossRef]

4. Sun, Y.L.; Ren, H.; Jiao, Q.J. Comparison of thermal behaviors and decomposition kinetics of NEPE propellant before and after storage. J. Therm. Anal. Calorim. 2018, 131, 101-111. [CrossRef]

5. Yim, Y.J.; Jang, M.W.; Park, E.Y.; Lee, J.S.; Han, H.; Lee, W.B.; Song, S.H.; Kim, M.T.; Yoo, J.C.; Yoon, M.W. Infrared irradiance reduction in minimum smoke propellants by addition of potassium salt. Propell. Explos. Pyrot. 2015, 40, 74-80. [CrossRef]

6. Gao, D.X.; Huang, J.; Lin, X.H.; Yang, D.L.; Wang, Y.J.; Zheng, H.Y. Phase transitions and chemical reactions of octahydro-1,3,5,7-tetranitro-1,3,5,7-tetrazocine under high pressure and high temperature. RSC Adv. 2019, 9, 5825-5833. [CrossRef]

7. Tarver, C.M. High Energy Materials, Propellants, Explosives and Pyrotechnics, Jai Prakash Agrawal. Propell. Explos. Pyrot. 2010, 35. [CrossRef]

8. Wei, T.T.; Zhang, Y.; Xu, K.Z.; Ren, Z.Y.; Gao, H.X.; Zhao, F.Q. Catalytic action of nano Bi2WO6 on thermal decompositions of AP, RDX, HMX and combustion of NG/NC propellant. RSC Adv. 2015, 5, 70323-70328. [CrossRef]

9. Gao, Y.; Ao, W.; Chen, S.W.; Kong, J.; Wang, Y.; Zhang, Q.H.; Yan, Q.L. Effects of nanosized metals and metal oxides on the thermal behaviors of insensitive high energetic compound ICM-102. J. Phys. Chem. C 2019, 123, 31108-31118. [CrossRef]

10. Shao, E.S.; Li, D.D.; Li, J.Z.; Zhang, G.F.; Zhang, W.Q.; Gao, Z.W. Mono- and dinuclear ferrocenyl lonic complexes with polycyano anions. Characterization, migration, and catalytic effects on thermal decomposition of energetic complexes. Z. Anorg. Allg. Chem. 2016, 642, 871-881. [CrossRef]

11. Yang, Q.; Song, X.X.; Zhao, G.W.; Yang, G.L.; Yang, L.L.; Wei, Q.; Xie, G.; Chen, S.P.; Gao, S.L. A 3D cuii-based energetic MOF: Synthesis, structure, and energetic performance. Eur. J. Inorg. Chem. 2016, 2016, 5052-5056. [CrossRef]

12. Ma, X.H.; Cai, C.; Sun, W.J.; Song, W.M. Enhancing energetic performance of multinuclear Ag(I)-cluster MOF-based high-energy-density materials by thermal dehydration. ACS Appl. Mater. Interfaces 2019, 11, 9233-9238. [CrossRef] [PubMed]

13. Wang, Y.L.; Wei, Z.X.; Kang, L. Progress on combustion catalysts of solid propellant. Chin. J. Energ. Mater. 2015, 23, 89-98. [CrossRef]

14. Yan, Q.L.; Zhao, F.Q.; Kuo, K.K.; Zhang, X.H.; Zeman, S.; DeLuca, L.T. Catalytic effects of nano additives on decomposition and combustion of RDX-, HMX-, and AP-based energetic compositions. Prog. Energy Combust. Sci. 2016, 57, 75-136. [CrossRef]

15. Bu, R.P.; Li, H.Z.; Zhang, C.Y. Polymorphic transition in traditional energetic materials: Influencing factors and effects on structure, property, and performance. Cryst. Growth Des. 2020, 20, 3561-3576. [CrossRef]

16. Jeon, W.C.; Lee, J.H.; Kim, J.C.; Jung, S.H.; Cho, S.G.; Kwak, S.K. Controllable explosion of nanobomb by modifying nanocontainer and external shocks. J. Phys. Chem. C 2020. [CrossRef]

17. Chen, D.; Huang, S.L.; Zhang, Q.; Yu, Q.; Zhou, X.Q.; Li, H.Z.; Li, J.S. Two nitrogen-rich Ni(II) coordination complexes based on 5, 5'-azotetrazole: Synthesis, characterization and effect on thermal decomposition for RDX, HMX and AP. RSC Adv. 2015, 5, 32872-32879. [CrossRef]

18. Wei, J.P.; Zhang, D.; Yang, Q.; Chen, S.P.; Gao, S.L. 0D Cu (II) and 1D mixed-valence Cu (I)/Cu (II) coordination complexes based on mixed ligands: Syntheses, structures and catalytic thermal decomposition for HMX. Inorg. Chem. Commun. 2013, 30, 13-16. [CrossRef]

19. Zhao, C.D.; Chi, Y.; Yu, Q.; Wang, X.F.; Fan, G.J.; Yu, K. Comprehensive study of the interaction and mechanism between bistetrazole ionic salt and ammonium nitrate explosive in thermal decomposition. J. Phys. Chem. C 2019, 123, 27286-27294. [CrossRef] 
20. Yang, Q.; Ge, J.; Gong, Q.B.; Song, X.X.; Zhao, J.W.; Wei, Q.; Xie, G.; Chen, S.P.; Gao, S.L. Two energetic complexes incorporating 3, 5-dinitrobenzoic acid and azole ligands: Microwave-assisted synthesis, favorable detonation properties, insensitivity and effects on the thermal decomposition of RDX. New J. Chem. 2016, 40, 7779-7786. [CrossRef]

21. Han, J.; Li, T.; Li, B. A new nickel (II) coordination complex constructed by pyridyl-triazole and oxybis (benzoic acid): Synthesis, crystal structure and the effect on the thermal decomposition of ammonium perchlorate. Chin. J. Struct. Chem. 2015, 34, 253-259. [CrossRef]

22. Gao, W.J.; Liu, X.Y.; Su, Z.Y.; Zhang, S.; Yang, Q.; Wei, Q.; Chen, S.P.; Xie, G.; Yang, X.W.; Gao, S.L. High-energy-density materials with remarkable thermostability and insensitivity: Syntheses, structures and physicochemical properties of $\mathrm{Pb}$ (II) complexes with 3-(tetrazol-5-yl) triazol. J. Marer. Chem. A 2014, 2, 11958-11965. [CrossRef]

23. Tao, G.H.; Parrish, D.A.; Shreeve, J.M. Nitrogen-ich 5-(1-methylhydraziny) tetrazole and its copper and silver complexes. Inorg. Chem. 2012, 51, 5305-5312. [CrossRef] [PubMed]

24. Liu, X.Y.; Qu, X.N.; Zhang, S.; Ke, H.S.; Yang, Q.; Shi, Q.; Wei, Q.; Xie, G.; Chen, S.P. High-performance energetic characteristics and magnetic properties of a threedimensional cobalt(II) metal-organic framework assembled with azido and triazole. Inorg. Chem. 2015, 54, 11520-11525. [CrossRef] [PubMed]

25. Qu, X.N.; Zhang, S.; Wang, B.Z.; Yang, Q.; Han, J.; Wei, Q.; Xie, G.; Chen, S.P. An Ag(I) energetic metal-organic framework assembled with the energetic combination of furazan and tetrazole synthesis structure and energetic performance. Dalton Trans. 2016, 45, 6968-6973. [CrossRef] [PubMed]

26. Szimhardt, N.; Wurzenberger, M.H.H.; Zeisel, L.; Gruhne, M.S.; Lommel, M.; Stierstorfer, J. Maximization of the energy capability level in transition metal complexes through application of 1-amino-and 2-amino-5 H-tetrazole ligands. J. Mater. Chem. A 2018, 6, 16257-16272. [CrossRef]

27. Zhang, X.Q. Studies on the Synthesis, Crystal Structures, Spectroscopic Characterization and Magnetic Properties of Complexes of Tetrazole-1-Acetic Acid; Guangxi Normal University: Guilin, China, 2006.

28. Li, Q.Y.; Yang, G.W.; Tang, X.Y.; Ma, Y.S.; Yao, W.; Zhou, Y.F.; Chen, J.; Zhou, H. Constructions of a set of new lanthanide-based coordination polymers with hatza ligands (hatza $=5$-aminotetrazole -1 -acetic acid). Cryst. Growth Des. 2010, 10, 165-170. [CrossRef]

29. Qu, Y.Y.; Wei, Z.X.; Kang, L.; Xie, F.; Zhang, H.D.; Yue, P. Synergistic catalytic effect of a series of energetic coordination complexes based on tetrazole-1-acetic acid on thermal decomposition of HMX. Z. Anog. Allg. Chem. 2017, 643, 742-748. [CrossRef]

30. Xie, Y.S.; Tan, J.Y.; Hu, M.L. Application of nanotechnology in post-treatment of automobile tail gas nitrogen oxides. Nanosci. Nanotech. 2017, 1, 26-29. [CrossRef]

31. Papavasiliou, A.; Tsiourvas, D.; Deze, E.G. Hyperbranched polyethyleneimine towards the development of homogeneous and highly porous $\mathrm{CuO}-\mathrm{CeO}_{2}-\mathrm{SiO}_{2}$ catalytic materials. Chem. Eng. J. 2016, 300, 343-357. [CrossRef]

32. Wei, Z.X.; Wang, Y.; Zhang, X.J.; Hu, C.W. Combustion synthesis and effect of LaMnO3 and LaOCl powder mixture on HMX thermal decomposition. Thermochim. Acta 2010, 499, 111-116. [CrossRef]

33. Mazzeu, M.A.C.; Mattos, E.D.C.; Iha, K. Studies on compatibility of energetic materials by thermal methods. JATM 2010, 2, 53-58. [CrossRef]

34. Wang, Y.; Qiu, R.; Wang, Q.; Wang, E.Y.; Zhao, L.M.; Wang, P.; Chen, F.X.; Huang, J.L. Effects of novel energetic material NOG2Tz on thermal decomposition behavior of HMX. Chin. J. Chem. Eng. 2014, 22, $22-25$. [CrossRef]

35. Guo, W.X.; Han, Z.W.; Lin, Q.H.; Wang, B. Pre-formulation compatibility studies of 5-amino-1H-tetrazole nitrate with several typical materials by thermal and non-thermal techniques. Cent. Eur. J. Energ. Mater. 2018, 15, 100-114. [CrossRef]

36. De Lima, I.P.B.; Lima, N.G.P.B.; Barros, D.M.C.; Oliveira, T.S.; Mendonc, C.M.S. Compatibility study between hydroquinone and the excipients used in semi-solid pharmaceutical forms by thermal and non-thermal techniques. J. Therm. Anal. Calorim. 2015, 120, 719-732. [CrossRef]

37. Cheng, G.Z.; Zhu, C.F.; Zhang, M.T.; Li, C.; Yuan, G. Infrared absorption spectrum of evaporated water molecules in slit. Chin. J. Lumin. 2020, 41, 110-116. [CrossRef]

38. Wang, J.S.; Xu, M.C.; Li, C.; Yuan, G. Influence of infrared adsorption properties of sodium nitrate with silver/diamond powder (Ag/DP) composites. Spectrosc. Spect. Anal. 2017, 37, 2737-2742. [CrossRef] 
39. Nie, F.D.; Zhang, J.; Guo, Q.X.; Qiao, Z.Q.; Zeng, G.Y. Sol-gel synthesis of nanocomposite crystalline HMX/AP coated by resorcinol-formaldehyde. J. Phys. Chem. Solids 2010, 71, 109-113. [CrossRef]

40. Ordzhonikidze, O.; Pivkina, A.; Frolov, Y.; Muravyev, N.; Monogarov, K. Comparative study of HMX and CL-20. J. Therm. Anal. Calorim. 2011, 105, 529-534. [CrossRef]

41. Yong, G.P.; Zhang, Y.M.; Zhang, B. Hydrothermal syntheses, crystal structures and properties of novel quinone biradical and mixed-valence copper coordination polymer with semiquinone radical ligand generated in situ. Cryst. Eng. 2012, 14, 8620-8625. [CrossRef]

42. Liu, Z.R.; Liu, Y.; Fan, X.P.; Zhao, F.Q. Thermal decomposition of RDX and HMX explosives part III: Mechanism of thermal decomposition. Chin. J. Explos. Propel. 2006, 29, 14-18. [CrossRef]

43. Tarver, C.M.; Chidester, S.K.; Nichols, A.L. Critical conditions for impact-and shock-induced hot spots in solid explosives. J. Phys. Chem. 1996, 100, 5794-5799. [CrossRef]

44. Ye, C.C.; An, Q.; Zhang, W.Q.; Goddard, W.A., III. Initial decomposition of HMX energetic material from quantum molecular dynamics and the molecular structure transition of $\beta$-HMX to $\delta$-HMX. J. Phys. Chem. C 2019, 123, 9231-9236. [CrossRef]

45. Zhang, H.D.; Wei, Z.X.; Cao, X.F. Synthesis of a series of coordination compounds based on tetrazole-1-acetic acid and effect on HMX thermal decomposition. J. Shanxi Univ. (Nat. Sci. Ed.) 2020. [CrossRef]

46. Ai, L.H.; Zhang, C.H.; Li, L.L.; Jiang, J. Iron terephthalate metal-organic framework: Revealing the effective activation of hydrogen peroxide for the degradation of organic dye under visible light irradiation. Appl. Catal. B 2014, 148, 191-200. [CrossRef]

47. Jin, B.; Shen, J.; Peng, R.F.; Shu, Y.J.; Tan, B.S.; Chu, S.J.; Dong, H.S. Synthesis, characterization, thermal stability and sensitivity properties of the new energetic polymer through the azidoacetylation of poly (vinyl alcohol). Polym. Degrad. Stab. 2012, 97, 473-480. [CrossRef]

48. Li, J.Z.; Fan, X.Z.; Feng, X.P.; Zhang, F.Q.; Han, R.Z. Compatibility study of 1,3,3-trinitroazetidinewith some energetic components and inert materials. J. Therm. Anal. Calorim. 2006, 85, 779-784. [CrossRef]

49. Liao, N. Preparation and characterization of nanocomposite energetic material based on HMX and AP. Chin. J. Energ. Mater 2015, 23, 709-711.

(C) 2020 by the authors. Licensee MDPI, Basel, Switzerland. This article is an open access article distributed under the terms and conditions of the Creative Commons Attribution (CC BY) license (http://creativecommons.org/licenses/by/4.0/). 